presence of prominent longstanding personal values, often relating to independence, supported stability of preferences. Conclusions The stability of care preferences is influenced by experience, evolving awareness and family considerations, but is less influenced by time or health changes in this population. By exploring health awareness and care experiences with patients, clinicians may be better able to elicit preferences and deliver care responsive to preferences following acute illness.

\section{CULTURAL RESPONSES TO PROSTATE CANCER IN GHANA: MASCULINITY AND STIGMA}

Yakubu Salifu, Kathryn Almack, Glenys Caswell. University of Nottingham, University of Hertfordshire

10.1136/bmjspcare-2019-ASP.108

Background Almost two-thirds of cancer deaths occur in developing countries. In resource-poor countries where there are no well-developed institutional-based palliative care services or where those facilities are in limited supply, family homebased care is a critical element of providing comforting care for patients whose prostate cancer has spread to other parts of the body (advanced). One in $8 \mathrm{men}$ in the UK develops prostate cancer.

Method The study adopted a qualitative repeat in-depth interview approach to explore the complexity of viewpoints. A total of 23 patients with advanced prostate cancer (APC), 23 family caregivers, and 12 health care professional yielded 68 interviews to get a holistic understanding of such care. Patients and their caregiver(s) participated in two interviews either individually or as joints across a period of up to 6 months. The interviews were transcribed and an inductive thematic analysis approach was used to explore relevant content and contexts of commonly recurring themes regarding the experiences stigma and how prostate cancer impacts on men's masculinity.

Findings Physical changes, impotence, incontinence, and loss of social status impacts on what means to be a real man. APC affects masculinity results in changed identity that affect the masculine role as leaders, breadwinners, and head of households. This together with impotence made the men felt 'not man enough 'and 'living dead' thereby impacting on their social statuses. APC is stigmatised as a promiscuous disease. The cultural response to prostate cancer should guide any self-management services for men living with prostate cancer. Conclusion This study has identified the cultural response to prostate cancer and how it influences their quality of life and dignity. This study provides rich experiences about living with prostate cancer issues around cultural responses that may hinder health-seeking and quality of care.

\section{Service Development | Posters 86 - 128}

\section{MOVING TOWARDS AN ENHANCED COMMUNITY PALLIATIVE SUPPORT SERVICE (ENCOMPASS): IMPACT OF USING MOBILE TECHNOLOGY TO SUPPORT DELIVERY OF COMMUNITY PALLIATIVE CARE}

Paul Taylor, Susan Mawson, Steven Ariss. University of Sheffield, St Luke's Hospice Sheffield

10.1136/bmispcare-2019-ASP.109
Background Models of community palliative care delivery are typically dependent on specialist nursing and medical staff acting independently. This study, part of the EnComPaSS project, appraises the impact of eShift, a technological system created by Sensory Technologies. eShift supports a delegated model of care, facilitating visiting staff to remain in ongoing contact with senior team members, and supporting systematic MDT recording.

Methods This was a service evaluation conducted at a Specialist Palliative Care service in the North of England, part of a real-world evaluation of a complex intervention. Prior data was collected from October 2014 to September 2015, transition to the new model began in October 2015, with data collection continuing to September 2016. Outcomes were based on prior hypotheses, including absolute numbers of patient contacts, grade of professional, number and route of hospital admissions and associated economic impact. Further evaluations over a longer time period are ongoing.

Results In comparing the pre-intervention period with the follow-up period, the total number of patients on the caseload remained relatively stable (1521 vs 1501). There was a reduction in total visits (3725 vs 3285 ), number of consultant visits (105 vs 48) and number of senior nurse visits (3361 vs 2730). There was an increase in the number of band 5 nurse (0 vs 208) and registrar visits (89 vs 170). Furthermore, number of patients admitted to hospital reduced (1238 vs 1156), as did overall admissions (5571 vs 4548) and average length of stay in days (6.23 vs 5.99). The reduction in hospital bed-days translates to a cost saving of $£ 2.7 \mathrm{~m}$ per year, based on costs during the study period.

Conclusion This service evaluation supports the successful implementation of a technological solution to improving efficiency and delivery of community palliative care, with associated reductions in visits, hospital stays and service costs.

\section{WHAT FACTORS ULTIMATELY INFLUENCE THE PLACE OF DEATH OF CARE HOME RESIDENTS? A QUALITATIVE STUDY OF THE INTERACTION BETWEEN CARE HOMES AND GENERAL PRACTITIONERS IN THE SOUTH WALES VALLEYS}

Ian Jones, Dylan Harris. Glyn Ebwy Surgery - Ebbw Vale, University of UK

\subsection{6/bmjspcare-2019-ASP.110}

Background In Wales, over 50\% of care home patients at end of life die in hospital. Initiatives such as advance care planning aim to reduce hospital admissions from care homes at end of life, but improvements have been slow. This study explores why some care home patients are admitted to hospital at end of life, and why similar patients are looked after in their care homes.

Methods The study is a retrospective, thematic analysis of interviews with General Practitioners (GPs) and care home staff. The interviews were based on care home deaths occurring in 6 GP surgeries, 6 nursing homes and 6 residential homes in the South Wales valleys between 01/09/2016 and 31/08/2017.

Results Fifty-seven hospital deaths were discussed, along with a similar number of care home deaths. Overall, $78 \%$ of patients overall died an expected death in their care homes. 